\title{
Get her off my screen: taste-based discrimination in a high-stakes popularity contest
}

By Tom Lane

School of Economics, University of Nottingham Ningbo China, 199 Taikang East Road, Ningbo, China, 315100; e-mail: Tom.Lane@nottingham.edu.cn

JEL classifications: D01, D72, J14, J15, J16 


\section{Abstract}

This study tests for taste-based discrimination in a high-stakes popularity contest. Data is taken from audience voting in six countries on the reality television show Big Brother, a setting where statistical discrimination can play no role. The audience votes over which contestants remain on the show, the winner of which earns a large cash prize; I test whether voters discriminate by gender, race and age. Results show a striking taste for discrimination against women: being female makes an eligible contestant significantly more likely to lose an audience vote in five of the seven versions of Big Brother analysed. There is also evidence of a taste for discrimination against non-white contestants amongst audiences in Germany, Italy and the UK. However, little support is found for taste-based age discrimination. I present evidence that the levels of discrimination identified are robust to differences in the types of contestant appearing on Big Brother. 


\section{Introduction}

The oldest economic theory of discrimination is Gary Becker's taste-based model (Becker, 1957). According to this theory, individuals discriminate simply because they prefer particular groups of people over others, and it pleases them to provide relatively favourable treatment towards those belonging to the more preferred groups. Such a theory is extremely intuitive, particularly as these discriminatory preferences could result from prejudice, which irrefutable evidence shows has existed, and continues to exist, in societies across the world (e.g. Dovidio and Gaertner, 1986; Strabac and Listhaug, 2008). As discrimination remains an economic issue with extremely serious consequences for those disadvantaged by it (e.g. Wallace et al, 2016; Blau and Kahn, 2017), a strong interest in the topic endures amongst the economic profession; and, in explaining discriminatory outcomes, taste-based models remain popular.

However, identifying where taste-based discrimination exists is empirically challenging because of the possible confounding presence of statistical discrimination. Theories of statistical discrimination, which comprise the other popular conceptual strand of economic thought on discrimination (originating with Arrow, 1972), hold that discriminatory outcomes occur not because individuals have any preference towards people of one or another group, but simply due to them attempting to maximize their material payoffs from economic interactions. In interactions where an individual's payoff-maximising behaviour depends on the characteristics of others, but where these characteristics are not perfectly observable, the individual will construct probabilistic beliefs about the others' characteristics based on their group identities. If the individual believes characteristics differ on average between different groups, this can result in him or her adopting different behaviours towards members of these different groups. Isolating taste-based from statistical discrimination can be very difficult, not least because it is rare that one can observe discriminatory behaviour in a natural environment where the discriminators' own material payoffs are unaffected by their actions, rendering statistical motives for discrimination irrelevant and therefore allowing the conclusion that the discrimination must be taste-based. ${ }^{1}$

For some years, empirical economic research often avoided attempting to distinguish between taste-based and statistical discrimination, but more recently interest in doing so has grown (Guryan and Charles, 2013). Knowing whether discrimination is driven by tastes or statistical beliefs not only enhances our understanding of human behaviour, but is also helpful to those seeking insight into which type of policies can effectively tackle discrimination. Economic researchers have particularly turned to lab experiments, where the taste for discrimination can be clearly isolated (e.g. Ruffle and Sosis, 2006; Chen and Li, 2009; Chuah et al., 2013). This literature suggests both taste-based and statistical discrimination are important, with the relative importance of each varying across different contexts (Lane, 2016). However, measuring such a sensitive phenomenon as discrimination in the lab carries its own problems, wherein observer scrutiny may bias experimental subjects towards socially desirable behaviour. Therefore, opportunities to isolate the taste for discrimination using naturallyoccurring data are welcome when they arise.

\footnotetext{
${ }^{1}$ In economic research, taste-based discrimination conventionally captures all discrimination which cannot be explained as driven by statistical beliefs. One view of discrimination which is increasingly influential in economics is that it can be driven by implicit (subconscious) bias (e.g. Bertrand et al, 2005). Such bias need not be regarded as an alternative to tastes or differential statistical beliefs, but can be viewed as a possible source of either. For instance, Price and Wolfers (2010) argue that implicit bias lies behind a taste for racial discrimination amongst basketball referees.
} 
This study measures taste-based discrimination in one such natural setting, where it cannot be confounded by statistical discrimination. Specifically, I test for discrimination in audience voting on Big Brother, a reality television show where a group of contestants (housemates) live together in a house for a period of weeks or months, isolated from the outside world. At regular intervals, viewers vote to 'evict' housemates; the last contestant to avoid eviction is deemed the show's winner and earns a large cash prize.

This environment provides an ideal opportunity to test for taste-based discrimination. Since the audience's own material payoffs cannot be affected by which housemate is evicted, there is no scope for statistical discrimination, and therefore any discrimination in their voting must be tastebased. The prize for the show's winner also means the eviction decisions have substantial economic consequences, with stakes much higher than those typically used in lab experiments. Furthermore, the globalisation of the Big Brother franchise, and its long-running nature, allows in this study for discrimination to be tested separately on large datasets taken from six different countries.

This paper measures the taste for discrimination on the basis of three identity characteristics: gender, race and age. While a huge literature documents the existence of racial discrimination (e.g. Arrow, 1998; Zschirnt and Ruedin, 2016), uncertainty remains over whether - or in which circumstances - this is driven by tastes rather than statistical beliefs. In the experimental literature, some studies have found a taste for racial discrimination (e.g. Ferraro and Cummings, 2007; Der Merwe and Burns, 2008), but others have found little evidence of it (e.g. List, 2004; Fong and Luttmer, 2011; Friesen et al, 2012). An experiment by Burns (2006) found evidence both of a taste for discrimination amongst some racial groups and a taste for out-group favouritism amongst others. A taste for out-group favouritism also fits with the results of Aldrich et al. (2005), who found a positive effect of black players in American football matches on television ratings. Other studies on naturally-occurring data provide mixed evidence on the presence of a taste for racial discrimination. For instance, Knowles et al. (2001) concluded that racial discrimination by US police was statistical and not taste-based; a similar position was taken by Ewens et al. (2014) in relation to racial discrimination by US landlords. On the other hand, Charles and Guryan (2008) and Carlsson and Rooth (2012) have used social survey data to produce evidence consistent with a taste for racial discrimination. The mixed evidence over the presence of a taste for racial discrimination provides motivation for searching for one amongst Big Brother viewers.

As with discrimination against racial minorities, discrimination against women has been well documented (e.g. Riach and Rich, 2002; Jarrell and Stanley, 2004). However, this has largely been investigated in the context of markets, where it is not clear whether the discrimination is tastebased or statistical. Experiments have tended to find no evidence of a taste for gender discrimination (Ortmann and Tichy, 1999; Solnick, 2001) or limited evidence of a taste for discriminating in favour of the opposite gender, whether male or female (Eckel and Grossman, 2001; Büchner and Dittrich, 2002; Ben-ner et al., 2004; Houser and Schunk, 2009; Slonim and Guillen, 2010). Non-experimental evidence on taste-based gender discrimination is scarce; Marom et al. (2016) found some evidence of taste-based discrimination by men towards women in crowdfunding, while Atanasov and Dana (2013) found both men and women have a preference for favouring their own gender on the gameshow The Price Is Right. The inconsistent evidence over the taste for gender discrimination makes this an interesting question to pursue in the context of Big Brother audience voting.

Age discrimination has not been as widely studied as racial and gender discrimination, but what research exists has tended to find strong discrimination against older people (e.g. Riach and Rich, 2010; Ahmed et al., 2012). Very little research has investigated whether this discrimination is taste- 
based or statistical. However, List (2006) finds evidence of a taste for discrimination against old contestants on the gameshow Friend or Foe. The shortage of evidence about taste-based age discrimination makes this also an interesting question to pursue in the context of Big Brother audience voting.

This study's results show a striking taste for discrimination against female contestants. In four of the seven versions of Big Brother analysed there is strong evidence that, among contestants facing audience votes, being female makes one more likely to lose, with a fifth version also providing weak evidence of such an effect. Also identified is a taste for discrimination against non-white contestants, an effect which is strongly significant in two versions of Big Brother and weakly significant in one. However, there is little evidence of discrimination on the basis of age; only in the Italian version of Big Brother does being older make a contestant significantly more likely to lose an audience vote. I run robustness checks showing that levels of discrimination do not increase over the years analysed (2000-2016) and are similar between the regular and celebrity versions of the UK show, suggesting voter behaviour is not substantially affected by changes in the characteristics of the contestant pool, and therefore hinting that the results are not driven simply by the type of contestants appearing on Big Brother.

This paper contributes to the economic literature on discrimination, measuring the tastes of Big Brother viewers for discriminating against non-whites, women and older people. A key contribution is in identifying a setting where there is strong discrimination against women which is unambiguously taste-based, a finding not often made in previous research. The large effect sizes estimated on gender discrimination would, if generalized to other contexts, have substantial economic consequences. A taste for discrimination against women could help explain economic inequality between men and women in society, and a particular implication of this study, given its setting, could be that a taste for discrimination lies behind society's apparently harsh treatment of women in the entertainment industry (e.g. Williamson, 2010). This study also adds weight to the existing evidence for taste-based racial discrimination, and provides a rare attempt at investigating taste-based age discrimination.

This study furthermore contributes to the literature investigating discrimination through the behaviour of television viewers. This literature includes research on the effect on viewing figures of the characteristics of sports players (Kanazawa and Funk, 2001; Aldrich et al., 2005; Meier and Leinwather, 2013; Jane, 2015; Meier and Konjer, 2015) or TV presenters (Myers, 2008). More closely related to this paper is Lee (2009), who finds evidence of racial discrimination in audience voting on the reality television show American Idol. ${ }^{2}$ Apart from focusing on a different reality show, this paper differs from the latter by investigating discrimination along multiple identity lines, and by focusing on different countries.

\section{Data and empirical strategy}

Big Brother is a reality TV show with a gameshow-like format. In each series of the show, contestants live together in a house for a period of weeks or months, filmed constantly, unable to leave and with

\footnotetext{
2 There have been several studies measuring discrimination from the behaviour of contestants on reality television shows (Dilks et al., 2010; Wall, 2011; Ahmed, 2013; Schüller et al., 2014; Lane, 2018). Research has also used behaviour on gameshows to estimate discrimination (Levitt, 2004; Antonovics et al., 2005; List, 2006; Anwar, 2012; Belot et al., 2012; Hamermesh, 2012; Atanasov and Dana, 2013).
} 
no contact with the outside world. At regular intervals housemates nominate who amongst themselves should face eviction. The housemates who receive the most nominations (generally those finishing equal-second or higher in the nominations rankings, although this threshold is sometimes lowered) subsequently face an audience vote. Voting is done by viewers registering their choices by telephone or, in more recent series, online. Of the nominated housemates, the person or, in occasional twists, more than one person - receiving the lowest public support to remain in the house is evicted. In the final round of the series, all remaining housemates face the audience vote, with the one receiving the most votes deemed the winner and collecting a large cash prize. ${ }^{3}$

Since originating in the Netherlands in 1999, versions of Big Brother have been made in many different countries. The requirement for inclusion in this paper is that a version had at least ten series of data available by 2016 . This is to ensure reasonably well-powered statistical analysis can be performed on the data, as each version of the show will be analysed separately. The selected versions are from Australia, Brazil, Germany, Italy, Spain and the UK; the UK provides two versions, as in addition to the regular show the country has also produced a long-running version featuring exclusively celebrity contestants. ${ }^{4}$

To investigate contestants' popularity with the public, I collect data on which housemate loses each audience vote. This information is drawn from the entertainment fandom website Wikia (for the UK versions, except the tenth series of the celebrity version) and Wikipedia (for the tenth UK celebrity series, and all series from the other countries). In general using such sources of data could be problematic, as these websites are compiled by public contributors and can be edited by anyone. However, for the purposes of this study, there are good reasons to believe they are reliable. First, the information on nominations and evictions is presented on both websites in a tabular form (see Figure A1 in the online Appendix for an example); if the wrong person was listed as being evicted in one round of voting, it would not be possible for contributors to correctly input the following round of nominations, so the mistake would likely be spotted and rectified. Furthermore, in a separate study on nominations in the UK versions of Big Brother, I cross-checked 200 nominations by watching YouTube footage of the episodes and found that in every case the information on Wikia or Wikipedia was accurate (Lane, 2018).

How the loser of an audience vote is defined depends on the way viewers are instructed to vote. Generally, in an audience vote before the final week, viewers are instructed to vote for the person they want to evict, so there I define the loser as the person receiving most votes. On some occasions, however, the viewers are told to vote for one person they want to save, in which case the loser is defined as the contestant receiving least votes ${ }^{5}$. In the final week, when viewers vote for the person they want to win, the contestant receiving least votes is defined as the loser.

\footnotetext{
${ }^{3}$ In the versions of the show analysed in this paper, the prizemoney has ranged between $f 50,000$ in some UK series to $€ 1,000,000$ in one German series. In the UK celebrity series, the prizemoney is donated to the winner's charity of choice. Even so, large personal financial benefits undoubtedly accrue to the winning celebrity in terms of the boost to their public image.

${ }^{4}$ Despite running for many series, the USA version is not included because it uses a different format from other countries, with no audience voting over evictions.

${ }^{5}$ In both cases, the person defined as the loser is evicted. Occasionally, when multiple eviction twists are introduced, the next least popular housemate(s) is also evicted. For consistency, however, I will always define there as being only one loser per vote.
} 
The dependent variable, labelled Loser, is a binary variable. It takes the value of 1 for the housemate who loses a given audience vote, and 0 for all other housemates who contest the audience vote and do not lose it (existing housemates who survive the nomination process so that they do not contest the audience vote are not included in the data). This method of modelling the data was preferable given that the sources I use do not often provide information on the precise share of votes each contestant receives. Audience votes are thus modelled as a discrete choice problem for viewers, who in a given round of voting collectively select a loser from a set of alternatives (i.e. contestants facing the audience vote) with differing attributes (i.e. personal characteristics). I analyse the data using conditional logit regressions, which estimate the effects an alternative's attributes have on the probability of this alternative being selected. In this case, the conditional logit estimates the effects an eligible contestant's personal characteristics have on the probability of them losing a given audience vote. Standard errors in the models are corrected for heteroscedasticity, with all rounds of voting within a particular series treated as providing a cluster of observations.

The total number of observations in the final datasets, and the number of rounds of voting and series from which they are taken, are presented in Table 1. One observation corresponds to one eligible contestant in a given audience vote. Not all rounds of audience voting from all series are included. Specifically, audience votes which do not relate to evictions or determining the show's winner are not included. These occur during occasional twists - for example when audience votes

Table 1: Summary of data

\begin{tabular}{|l|ccccccc|}
\hline & Australia & Brazil & Germany & Italy & Spain & $\begin{array}{c}\text { UK } \\
\text { regular }\end{array}$ & $\begin{array}{c}\text { UK } \\
\text { celebrity }\end{array}$ \\
\hline Series in data & 11 & 16 & 12 & 11 & 14 & 17 & 18 \\
Rounds of voting & 133 & 217 & 191 & 156 & 183 & 159 & 78 \\
Observations & 532 & 496 & 639 & 500 & 672 & 554 & 323 \\
\% Female & 50.4 & 51.0 & 48.5 & 44.8 & 50.3 & 44.6 & 50.5 \\
\% Non-white & 9.6 & 25.0 & 9.2 & 2.6 & 6.7 & 23.1 & 14.6 \\
$\begin{array}{l}\text { Mean age } \\
\text { (Std. dev.) }\end{array}$ & $\begin{array}{l}25.1 \\
(5.3)\end{array}$ & 28.1 & 27.6 & 27.1 & 27.1 & 26.9 & 38.2 \\
\hline
\end{tabular}

Notes: Table 1 summarizes the datasets for each version of Big Brother. The statistics in the bottom three rows are calculated on the basis of all observations, not all individuals within the data (one person can appear in the data multiple times). Source: author's calculations based on data from Wikipedia, Wikia, World of Big Brother and Namepedia.

are held to decide which contestant is moved to a secret room within the house. Another occasional twist leads to the audience voting over which housemates will be nominated, with the other housemates then being required to choose to evict one of the nominees - this is included, as here the audience's vote strongly affects the probability of a housemate being evicted. Also included are audience votes to select between applicants vying to enter the competition as new housemates.

Another category of excluded data relates to rounds of voting where housemates are put into pairs and the audience must select which pair they want to be collectively evicted. Data is also excluded if none of the sources provide sufficient information from which to discern which housemate was the 
loser of a given vote. In particular, no data is available on any audience votes from the Italian series 12-14.

\subsection{Independent variables}

Photos of contestants, as well as age data, are taken from Wikia (Australia series 10-11, Spain series 13-14, all UK series except the tenth celebrity series), Wikipedia (Australia series 10-11, UK celebrity series 10) and World of Big Brother, another entertainment fandom site (Australia series 1-9, Spain series 1-12, Italy series 1-11, all German and Brazilian series). The regressions I estimate include as independent variables:

Female: A dummy variable equal to 1 if the housemate is female, and equal to 0 otherwise. Gender is coded on the basis of the photos or, if these are unclear, names. ${ }^{6}$

Non-white: A dummy variable equal to 1 if the housemate is non-white and equal to 0 if they are white. ${ }^{7}$ I did not code the race of non-white housemates, for practical and conceptual reasons. Nonwhite housemates make up only $12.6 \%$ of observations across all series; in the Brazilian series, where they are most prominent, they still provide only $25 \%$ of observations (see Table 1 ). Non-white housemates represent a wide variety of different racial groups, and many are mixed race, which would make coding their race difficult, and there would be insufficient data on most racial categories to run well-powered tests. In all of the featured countries except Brazil, a large majority of the viewership will be white, so categorising contestants as white or non-white separates them into a meaningful in-group and out-group from the perspective of most voters. I coded race first on the basis of the photos, defining as white those who appear to be of solely European ancestry - to minimize any potential biases I did this before collecting the audience vote data in order to be able to make borderline decisions blind to the effects they would have on my results. I subsequently also coded on the basis of housemates' names. Housemates' first names were searched for on an online name database, Namepedia; the surnames of male housemates were also searched for (I did not do this for female housemates, as their surnames are more likely to have changed through marriage). I redefined as non-white any housemate whose first name or surname is defined by Namepedia as being of non-European origin and not also of European origin. ${ }^{8}$

Age: The housemate's age in years.

\section{Results}

Table 2 presents the results of conditional logit regressions run on the dependent variable Loser. Odds ratios on the independent variables indicate the effects these variables have on the odds of an individual losing a given audience vote (where the odds is the ratio of the probability of them losing to probability of them not losing). An odds ratio above 1 implies a variable increases the odds - and therefore the likelihood - of an individual losing a given vote, while an odds ratio below 1 implies it

\footnotetext{
${ }^{6}$ Transgender housemates have occasionally appeared on Big Brother. The variable Female captures gender, rather than biological sex: I code it according to the category housemates appear to self-identity with.

${ }^{7}$ Note that I focus on race (which is defined by biology) rather than ethnicity (which is associated with culture).

${ }^{8}$ This name-based approach resulted in only eight housemates being re-coded as non-white. All the important results in this paper would remain qualitatively unaffected if race were coded based on photos alone (output is available on request).
} 
reduces it. Each model includes data from a particular version of Big Brother, as indicated in the top panel of the table.

The variable Female is positive and significant in five of the seven versions of the show. In Germany, Italy and the UK - both regular and celebrity versions - the variable is significant at the $1 \%$ level, strongly indicating that being female makes a housemate more likely to lose an audience vote. The effects are qualitatively large in magnitude. For instance, in the regular UK version the odds ratio is 2.272 - the highest found across all versions of the show - which indicates being female more than doubles the odds of a contestant losing a given audience vote. Only in the Australian and Brazilian versions of Big Brother does being female not make one significantly more likely to lose an audience vote, while in the Spanish version being female makes one significantly more likely to lose but only at the $10 \%$ level. In total, the evidence suggests viewers in most versions of Big Brother have, on average, a taste for discrimination against women.

The variable Non-white is positive and significant in three of the seven versions of the show. In the UK regular version it is significant only at the $10 \%$ level, providing weak evidence that being nonwhite makes a housemate more likely to lose a given audience vote. In Germany and Italy, however, the evidence is much stronger, significant at the $1 \%$ level. In Italy the odds ratio is particularly extreme, suggesting that being non-white raises the odds of a contestant losing a given audience vote by a factor of 5.593. In the Australian, Brazilian, Spanish and UK celebrity versions, being nonwhite is not found to significantly affect the likelihood of losing an audience vote. There is, therefore, mixed evidence on the presence of a taste for discrimination amongst Big Brother viewers against non-whites. Note that the relative scarcity of non-white housemates in most versions of Big Brother mean the tests for racial discrimination are lower-powered than the tests for gender discrimination, which may partly explain why some of the odds ratios are not found to be significant despite being positive in every version of the show except the Spanish.

Age is not generally found to be a significant variable. In six of the seven versions of Big Brother, a contestant's probability of losing a given audience vote is not found to be significantly influenced by their age. Only in Italy is the variable positive and significant, at the $5 \%$ level; the odds ratio of 1.048 implies that a one year increase in a person's age is associated with a $4.8 \%$ increase in their odds of losing a vote. This means, for instance, that in Italian Big Brother, being 10 years older raises the 
odds of one losing a given audience vote by a factor of 1.504, while being 20 years older raises the odds by a factor of $2.554 .^{9} 10$

Table 2: Conditional logit regressions on odds of losing audience vote

\author{
Dependent variable $=$ Loser
}

(1)

(2)

(3)

(4)

Australia

Brazil

Germany

Italy

(5)

Spain

(6)

(7)

UK

UK

Regular Celeb

Female

1.097

0.960

$1.831 * * *$

$1.611 * * *$

$1.265^{*}$

$2.272 * * *$

$2.188 * * *$

(0.137)

(0.157)

(0.369)

(0.273)

(0.173)

(0.398)

(0.596)

Non-white

1.166
$(0.280)$

1.141

$2.545^{* * * *}$

$5.593 * * *$

0.915

$1.647 *$

1.500

(0.280)

(0.192)

(0.527)

(2.001)

(0.331)

(0.466)

(0.699)

Age

$\begin{array}{cc}1.006 & 0.996 \\ (0.0209) & (0.0136)\end{array}$

0.996
$(0.00987)$

$1.048 * *$

1.003

0.993

1.018

(0.0209)

(0.0189)

(0.0116)

(0.0142)

(0.0115)

\begin{tabular}{lccccccc} 
Pseudo $\mathrm{R}^{2}$ & 0.0015 & 0.0016 & 0.048 & 0.046 & 0.0041 & 0.0671 & 0.0511 \\
Observations & 532 & 496 & 639 & 500 & 672 & 554 & 323 \\
\hline
\end{tabular}

Notes: Table 2 presents conditional logit models, with odds ratios presented. Note that an odds ratio of more than 1 indicates a positive effect, while an odds ratio of less than 1 indicates a negative effect. The dependent variable indicates whether or not an individual loses a given audience vote. Each model includes data only from one version of Big Brother, as indicated in the top panel. Standard errors, in parentheses, are corrected for heteroscedasticity, clustering by series. $* * * \mathrm{p}<0.01, * * \mathrm{p}<0.05, * \mathrm{p}<0.1$. Source: author's calculations based on data from Wikipedia, Wikia, World of Big Brother and Namepedia.

\footnotetext{
${ }^{9}$ An interesting question is whether the levels of discrimination identified vary according to the changing demographics of the remaining pool of housemates. One might predict that when there are fewer female, non-white or older housemates, discrimination against them will be weaker (if, for instance, some viewers have a preference for the contestant pool containing diversity). This is tested by including interaction terms in the models; output is reported in the online Appendix. The models in Table A1 include the interaction between Female and the female proportion of remaining housemates; in Table A2 they include the interaction between Non-white and the non-white proportion of remaining housemates; in Table A3 they include the interaction between Age and the average age of remaining housemates. Since discrimination levels could also be a function of how far into the series a vote takes place (which is likely to correlate with the remaining demographic proportions), as controls these models also include the interaction between the relevant variable (Female, Non-white or Age) and the audience voting round number in the current series. The interaction between Female and female proportion is only significant in the Australian and German versions, both at the $10 \%$ level, providing weak evidence that discrimination against women is stronger when the proportion of female housemates is higher. There is no significant evidence that discrimination against non-whites depends on the proportion of non-white housemates in any of the versions. In the Brazilian version, discrimination towards older housemates is found to be significantly stronger, at the $5 \%$ level, when the average age of housemates is higher, but the average age of housemates does not significantly affect age discrimination in any of the other versions.

${ }^{10}$ It would also be interesting to test for discrimination on the basis of social class. In principle this can be defined using housemates' occupations. However, such information is not consistently available or sufficiently clear for most of the versions of Big Brother this paper studies. For the UK regular series, it is feasible to code housemates' occupations into those which do or do not generally require university education. However, no significant discrimination is found on the basis of this variable (see Table A4 in the online Appendix).
} 


\subsection{Robustness checks}

The evidence above suggests that viewers of most of the analysed versions of Big Brother have on average a taste for discrimination against female contestants, while viewers of some of the analysed versions have on average a taste for discrimination against non-white contestants. An important question is how well these findings would hold up if the pool of individuals amongst which viewers are voting differed from the sample selected for participation on Big Brother. One might question, for instance, whether the discrimination against women and non-whites is a product of the unrepresentativeness of the contestants on the show - perhaps, viewers find the type of women and non-whites who compete on Big Brother particularly annoying - and therefore whether the same result would be found if the contestants were a representative sample drawn from the wider population.

Here, I present two pieces of suggestive evidence that the levels of discrimination identified are not meaningfully altered by changes in the type of contestants appearing on Big Brother. First, I plot the levels of gender, race and age discrimination over time. It is widely believed that in the early years of Big Brother the contestants appearing on the show had more normal personalities and backgrounds than in later years, when they had become increasingly outrageous. ${ }^{11}$ This is reflected somewhat by looking at the occupations of housemates upon their entering the show, which for some series are listed in the data sources used. Table A5 in the online Appendix reports these occupations for both the first series and the most recent included series of the versions of Big Brother I analyse. ${ }^{12}$ In general, the array of occupations represented in the first series does not come across as unrepresentative in any obvious way, but in the most recent series there is a large contingent whose backgrounds are in the entertainment or fashion industries, or whose occupations are otherwise unusual or sensationalist (the exception is in the Brazilian version where this is already the case in the first series, with three models, a dancer, a singer and an actress). The most extreme case is the regular UK version, where the housemates of the most recent series included seven models, a dancer, a nightclub hostess, a kickboxing world champion, a private investigator and the former owner of an escort agency, as well as another housemate who had already appeared on a different reality television show. The large cast of the most recent Italian series included four models, two dancers, a singer, a radio host and a footballer, while in Germany there were two models, a dancer, an actress and a stripper.

If the contestants' unrepresentativeness was the reason for the viewer discrimination, we should expect it to emerge less strongly in the initial years when they were more representative. To investigate this, I pool the data from all seven versions of Big Brother and run separate conditional logit regressions for each year of data. Figure 1 presents the odds ratios estimated on Female, Nonwhite and Age in each year. The evidence does not suggest gender or racial discrimination

\footnotetext{
${ }^{11}$ For instance, an article on the UK version of Big Brother in The Telegraph (Hawksley, 2016) claimed of the early series: 'Back then, the housemates were chosen, not because of their self-consciously wacky haircuts or their controversial views, but because they represented different sections of society. All were people the viewer might recognise.' The article implies that the type of contestant changed gradually: 'Even by series six, when Big Brother was still on Channel 4, the show was attracting the rent-a-gob show-offs that have viewers reaching for the remote.'

${ }^{12}$ An exception is the German version, for which details on the second rather than first series are presented, as the data sources provide no occupation information on the first. Australia is excluded as the data sources provide no occupation information for later series, and the UK celebrity version is excluded because by the show's definition all housemates have celebrity occupations.
} 
decreases over time - in fact, some of the highest odds ratios on Female and Non-white are in the earliest years of the show, when the contestants are likely to have been more representative. ${ }^{13}$

Figure 1: Gender, race and age discrimination by year

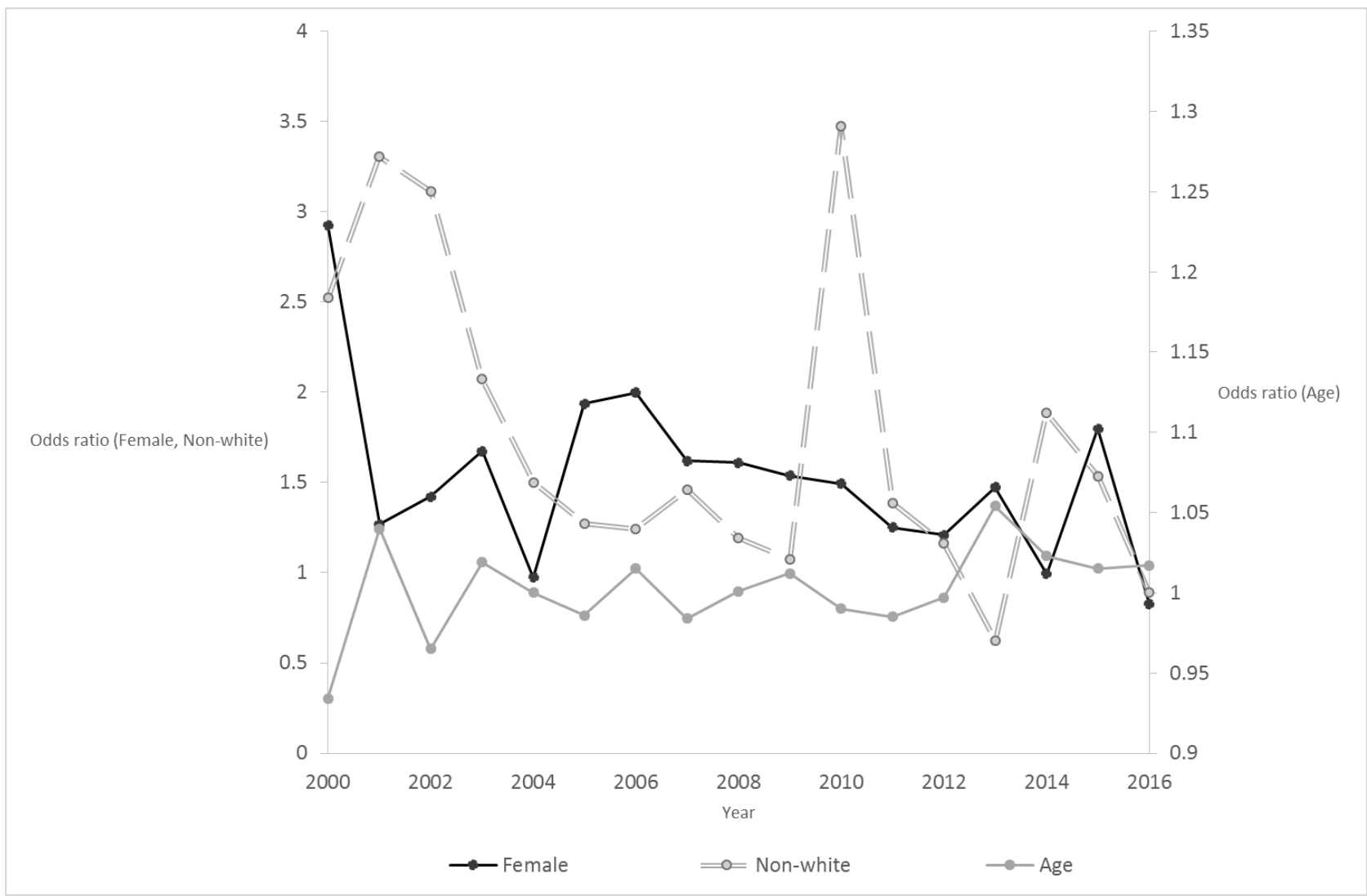

Notes: Figure 1 plots the odds ratios estimated on Female, Non-white and Age by logistic regressions taking data from all versions of Big Brother from the six countries in a given year. The dependent variable is whether or not an individual loses a given audience vote. An odds ratio above 1 indicates a positive effect, while an odds ratio below 1 indicates a negative effect. Source: author's calculations based on data from Wikipedia, Wikia, World of Big Brother and Namepedia.

A further check is whether discrimination differs between the regular and celebrity UK versions of Big Brother. While the characteristics of viewers of the two versions are likely to be similar, there may be differences between the types of contestants appearing on them. Not only might there be general differences between celebrities and non-celebrities (for example, see in Table 1 the higher average age in the celebrity series), these differences might also be compounded by differences in the recruitment process for the two versions of the show. Whereas for the regular series producers select amongst thousands of public applicants, for the celebrity series they invite and offer to pay famous people to participate, and these celebrities decide whether or not to accept the invitations. The two methods could lead to very different types of selectivity.

${ }^{13}$ In the online Appendix (Table A6), I test whether there are overall time trends on the levels of gender, racial and age discrimination. This is done by regressing the natural logarithms of the odds ratios presented in Figure 1 on the year they were estimated in. I control for the proportion of data in a given year coming from each version of Big Brother. There is no significant effect of year on the levels of gender or racial discrimination, while the level of age discrimination is found to increase over time but only at the $10 \%$ level. 
I test whether viewer discrimination differs between the regular and celebrity UK series by pooling the data from the two, and running conditional logit regressions with interaction terms. The results are presented in Table 3. The variables Female, Non-White and Age represent in turn gender, racial and age discrimination by viewers towards contestants in the regular series. The interaction terms between Celebrity and these variables show how much stronger or weaker such levels of discrimination are towards contestants in the celebrity series. An odds ratio of 0.963 on Celebrity $x$ Female, for instance, means the disadvantage of being female, in terms of the odds of losing a given audience vote, is 0.963 times as strong in the celebrity series as in the regular series. None of the interaction terms have statistically significant odds ratios, and a test of joint significance on the three interaction terms also produces a null result $(p=0.544)$. This confirms that the hypothesis of viewer discrimination being indistinguishable between the regular and celebrity UK series cannot be rejected, and is supportive of levels of discrimination generalising towards pools of contestants of differing characteristics.

Table 3: Conditional logit regression on odds of losing audience vote

Dependent variable: Nominated

Combined UK

Female

$2.272 * * *$

Non-white

Age

Celebrity x Female

Celebrity x Non-white

Celebrity x Age

Pseudo R ${ }^{2}$

0.0613

Observations

877

Notes: Table 3 presents a conditional logit model, with odds ratios presented. Note that an odds ratio of more than 1 indicates a positive effect, while an odds ratio of less than 1 indicates a negative effect. The dependent variable indicates whether or not an individual loses a given audience vote. The model includes data from only the UK regular and celebrity versions of Big Brother. Standard errors, in parentheses, are corrected for heteroscedasticity, clustering by series. $* * * \mathrm{p}<0.01$, ** $\mathrm{p}<0.05, * \mathrm{p}<0.1$. Source: author's calculations based on data from Wikipedia, Wikia and Namepedia. 


\section{Conclusion}

This study has tested for discrimination by gender, race and age in audience voting on seven versions of Big Brother. An important motivation for the study comes from the fact that, as the audience do not have own material payoffs contingent on their votes, the setting is one where statistical discrimination cannot occur and any discrimination identified is therefore necessarily taste-based. Furthermore, the stakes are high, so the consequences are economically meaningful. Discrimination against women is found to be strongly significant, and of a qualitatively large magnitude, in the German, Italian and UK (both regular and celebrity) versions of Big Brother; it is weakly significant in the Spanish version, and is not significant in the Australian and Brazilian versions. A taste for discrimination against non-whites is also strongly evident in Germany and Italy, and is weakly significant in the regular UK version, but is insignificant elsewhere. Discrimination on the basis of age is only evident in Italy, where older contestants are discriminated against.

The extent of the taste for discrimination against women is striking. At its most severe, in the UK versions, being female more than doubles the odds of losing an audience vote. Such levels of discrimination, if generalized to other contexts, would have substantial negative economic consequences for women. The finding is all the more striking given that previous evidence on the taste for gender discrimination has not tended to estimate such large effects. While some studies have identified taste-based gender discrimination (e.g. Atanasov and Dana, 2013; Marom et al., 2016), there has been a tendency for small effect sizes and often null results in the literature (e.g. Ortmann and Tichy, 1999; Solnick, 2001). However, previous research has generally focused on discrimination against the opposite gender, rather than against women in general. It cannot be said whether the discrimination against women identified in this study is driven by men or women. Anecdotal evidence suggests Big Brother viewers are disproportionately female, which might suggest favouritism towards the opposite gender is behind the results. ${ }^{14}$

The results suggest viewers have a greater tendency to dislike women on television than men. This could have important implications for the existence of gender discrimination in the entertainment industry. A taste for discrimination against women may be behind society's apparently scornful treatment of particular female celebrities (e.g. Williamson, 2010); it is argued, for instance, that the behaviour of female celebrities attracts more negative media coverage than that of male celebrities with similar lifestyles (Berkers and Eeckelaer, 2014). A taste for discrimination against women could also partially explain economic inequality between men and women in society more generally.

In general, this paper adds to previous research suggesting preferences help explain racial discrimination (e.g. Ferraro and Cummings, 2007; Charles and Guryan, 2008; Der Merwe and Burns, 2008). In particular, the evidence for racial discrimination in the German, Italian and UK versions of Big Brother suggests tastes are relevant to the discrimination found against racial or ethnic minorities in these countries (e.g. Klink and Wagner, 1999; Wood et al., 2009; Baldini and Federici, 2011). Although racial discrimination in the Australian and Brazilian versions of the show are not significant, the odds ratios are positive.

The evidence presented here does not suggest viewers in most countries are more or less prone to dislike old people on television than young people. Thus, while age discrimination may exist in the

\footnotetext{
${ }^{14}$ Rigorous data to support this claim is not available for this study, but the BBC reports that $70 \%$ of the viewers for the launch episode of the 2016 UK regular series (the version of Big Brother with the strongest estimated discrimination against women) were female (British Broadcasting Corporation, 2017).
} 
entertainment industry and across society more generally, the evidence of this paper is not indicative of a taste for it.

In general, the results differ across the different countries analysed. Although uncovering the reasons for these differences is beyond the scope of this study, one possibility is that the audience demographics differ. In particular, the insignificant racial discrimination in the Brazilian show may reflect the much higher proportion of non-whites in the Brazilian population (and likely, therefore, in the Brazilian audience) than in the populations (and audiences) of the other countries. Other macrolevel differences between the countries also may be in effect, and it is furthermore possible that although the essential format of the show is kept similar in all countries - some variability in discrimination results from small differences in the way different versions of Big Brother are organized.

Finally, I note that the sources of the tastes for discrimination presented in this paper are unknown. Big Brother represents a pure popularity contest in that viewers are not encouraged to vote on the basis of anything more specific than simply whom they like or not. The discrimination identified in this study can therefore be interpreted as representing group differences in basic likeability, as perceived by the audience. However, it cannot be said precisely why, in this case, certain groups are considered more likeable than others. It is impossible to comment, also, on whether the identified tastes for discrimination result from conscious or implicit bias (see e.g. Bertrand et al, 2005). Indeed, the underlying foundations of the tastes for discrimination remain a relatively underdeveloped research area in economics, and digging deeper into these will be a promising direction for future work.

\section{Supplementary material}

Supplementary material is available on the OUP website. These are the data and replication files, and the online appendix.

\section{Acknowledgements}

I would like to thank two anonymous referees for their helpful comments and suggestions on how to improve this paper. 


\section{$\underline{\text { References }}$}

Ahmed, A. (2013). Co-ethnic preferences in a cooking game: a study based on Come Dine With Me in Sweden. Ethnic and Racial Studies, 36, 2220-2236.

Ahmed, A. M., Andersson, L., and Hammarstedt, M. (2012). Does age matter for employability? A field experiment on ageism in the Swedish labour market. Applied Economics Letters, 19, 403-406.

Aldrich, E. M., Arcidiacono, P. S., and Vigdor, J. L. (2005). Do people value racial diversity? Evidence from Nielsen ratings. The BE Journal of Economic Analysis and Policy, 5.

Antonovics, K., Arcidiacono, P., and Walsh, R. (2005). Games and Discrimination Lessons From The Weakest Link. Journal of Human Resources, 40, 918-947.

Anwar, S. (2012). Testing for discrimination: Evidence from the game show Street Smarts. Journal of Economic Behavior and Organization, 81, 268-285.

Arrow, K. (1972). Some mathematical models of race discrimination in the labor market, in (A.H. Pascal, ed.), Racial Discrimination in Economic Life, pp. 187-204, Lexington, MA: D.C. Heath.

Arrow, K. J. (1998). What has economics to say about racial discrimination?. The journal of economic perspectives, 12, 91-100.

Atanasov, P., and Dana, J. (2013). The Price Is Sexist: Taste Based Discrimination by Contestants on the Price Is Right. Available at SSRN: http://dx.doi.org/10.2139/ssrn.1914911 (last accessed 31 October 2018).

Baldini, M., and Federici, M. (2011). Ethnic discrimination in the Italian rental housing market. Journal of Housing Economics, 20, 1-14.

Becker, G. S. (1957). The economics of discrimination, University of Chicago press, Chicago, IL.

Belot, M., Bhaskar, V., and Van De Ven, J. (2012). Beauty and the Sources of Discrimination. Journal of Human Resources, 47, 851-872.

Ben-Ner, A., Kong, F., and Putterman, L. (2004). Share and share alike? Gender-pairing, personality, and cognitive ability as determinants of giving. Journal of Economic Psychology, 25, 581-589.

Berkers, P., and Eeckelaer, M. (2014). Rock and roll or rock and fall? Gendered framing of the rock and roll lifestyles of Amy Winehouse and Pete Doherty in British broadsheets. Journal of Gender Studies, 23, 3-17.

British Broadcasting Corporation. (2017). Big Brother: Who is still watching it? 6 June 2017. https://www.bbc.com/news/entertainment-arts-40171096 (last accessed 31 October 2018)

Bertrand, M., Chugh, D., and Mullainathan, S. (2005). Implicit Discrimination. American Economic Review, 95, 94-98.

Blau, F. D., and Kahn, L. M. (2017). The gender wage gap: Extent, trends, and explanations. Journal of Economic Literature 55 (2017): 789-865.

Büchner, S., and Dittrich, D. A. (2002). I will survive!--Gender discrimination in a household saving decisions experiment (No. 2002-14). Max Planck Institute of Economics, Strategic Interaction Group, Jena. 
Burns, J. (2006). Racial stereotypes, stigma and trust in post-apartheid South Africa. Economic Modelling, 23, 805-821.

Carlsson, M., and Rooth, D. O. (2012). Revealing taste-based discrimination in hiring: a correspondence testing experiment with geographic variation. Applied Economics Letters, 19, 18611864.

Charles, K. K., and Guryan, J. (2008). Prejudice and wages: an empirical assessment of Becker's The Economics of Discrimination. Journal of political economy, 116, 773-809.

Chen, Y. and S. X. Li (2009). Group Identity and Social Preferences. American Economic Review 99: 431-457.

Chuah, S.-H., Fahoum, R., and Hoffmann, R. (2013). Fractionalization and trust in India: A fieldexperiment. Economics Letters 119: 191-194.

Der Merwe, V., and Burns, J. (2008). "WHAT'S IN A NAME? RACIAL IDENTITY AND ALTRUISM IN POST - APARTHEID SOUTH AFRICA." South African Journal of Economics 76: 266-275.

Dilks, L. M., Thye, S. R., and Taylor, P. A. (2010). Socializing economic theories of discrimination: Lessons from Survivor. Social Science Research, 39, 1164-1180.

Dovidio, J. F., and Gaertner, S. L. (1986). Prejudice, discrimination, and racism: Historical trends and contemporary approaches. Academic Press, Orlando.

Eckel, C. C., and Grossman, P. J. (2001). Chivalry and solidarity in ultimatum games. Economic Inquiry, 39, 171-188.

Ewens, M., Tomlin, B., and Wang, L. C. (2014). Statistical discrimination or prejudice? A large sample field experiment. Review of Economics and Statistics, 96, 119-134.

Ferraro, P. J. and R. G. Cummings (2007). Cultural diversity, discrimination, and economic outcomes: an experimental analysis. Economic Inquiry 45: 217-232.

Fong, C. M., and Luttmer, E. F. (2011). Do fairness and race matter in generosity? Evidence from a nationally representative charity experiment. Journal of Public Economics, 95, 372-394.

Friesen, J., Arifovic, J., Wright, S., Ludwig, A., Giamo, L., and Baray, G. (2012). Ethnic identity and discrimination among children. Journal of Economic Psychology 33: 1156-1169.

Guryan, J., and Charles, K. K. (2013). Taste-based or Statistical Discrimination: The Economics of Discrimination Returns to its Roots. The Economic Journal, 123, F417-F432.

Hamermesh, D. S. (2012). Tall or taller, pretty or prettier: is discrimination absolute or relative?. IZA Journal of Labor Economics, 1. https://doi.org/10.1186/2193-8997-1-2 (last accessed 31 October 2018).

Hawksley, R. (2016). Big Brother was once worth watching. No, really, it was. The Telegraph, 14 June 2016. http://www.telegraph.co.uk/tv/2016/06/14/big-brother-was-once-worth-watching-no-reallyit-was/ (last accessed 31 October 2018).

Houser, D., and Schunk, D. (2009). Social environments with competitive pressure: Gender effects in the decisions of German schoolchildren. Journal of Economic Psychology, 30, 634-641. 
Jane, W. J. (2015). Customer Discrimination and Outcome Uncertainty in the World Baseball Classic: The Case of the Taiwanese Television Audience. In The Sports Business in The Pacific Rim (pp. 103121). Springer International Publishing, Cham.

Jarrell, S. B., and Stanley, T. D. (2004). Declining bias and gender wage discrimination? A metaregression analysis. Journal of Human Resources, 39, 828-838.

Kanazawa, M. T., and Funk, J. P. (2001). Racial discrimination in professional basketball: Evidence from Nielsen ratings. Economic Inquiry, 39, 599-608.

Klink, A., and Wagner, U. (1999). Discrimination Against Ethnic Minorities in Germany: Going Back to the Field1. Journal of Applied Social Psychology, 29, 402-423.

Knowles, J., Persico, N., and Todd, P. (2001). Racial bias in motor vehicle searches: Theory and evidence. Journal of Political Economy, 109, 203-229.

Lane, T. (2016). Discrimination in the laboratory: A meta-analysis of economics experiments. European Economic Review, 90, 375-402.

Lane, T. (2018). Along which identity lines does 21st century Britain divide? Evidence from Big Brother. Unpublished manuscript, University of Nottingham Ningbo China.

Lee, J. (2009). American Idol: Evidence on same-race preferences. The BE Journal of Economic Analysis and Policy, 9.

Levitt, S. D. (2004). Testing theories of discrimination: evidence from Weakest Link. The Journal of Law and Economics, 47, 431-452.

List, J. A. (2004). The nature and extent of discrimination in the marketplace: Evidence from the field. The Quarterly Journal of Economics, 119, 49-89.

List, J. A. (2006). Friend or foe? A natural experiment of the prisoner's dilemma. The Review of Economics and Statistics, 88, 463-471.

Marom, D., Robb, A., and Sade, O. (2016). Gender dynamics in crowdfunding (Kickstarter): evidence on entrepreneurs, investors, deals and taste-based discrimination. Available at SSRN:

http://dx.doi.org/10.2139/ssrn.2442954 (last accessed 31 October 2018).

Meier, H. E., and Konjer, M. (2015). Is there a premium for beauty in sport consumption? Evidence from German TV ratings for tennis matches. European Journal for Sport and Society, 12, 309-340.

Meier, H. E., and Leinwather, M. (2013). Finally a 'Taste for diversity'? National identity, consumer discrimination, and the multi-ethnic German national football team. European sociological review, jct011.

Myers, C. K. (2008). Discrimination as a competitive device: The case of local television news. The BE Journal of Economic Analysis and Policy, 8.

Ortmann, A., and Tichy, L. K. (1999). Gender differences in the laboratory: evidence from prisoner's dilemma games. Journal of Economic Behavior and Organization, 39, 327-339.

Price, J., and Wolfers, J. (2010). Racial discrimination among NBA referees. The Quarterly journal of economics, $125,1859-1887$. 
Riach, P. A., and Rich, J. (2002). Field experiments of discrimination in the market place. The economic journal, 112.

Riach, P. A., and Rich, J. (2010). An experimental investigation of age discrimination in the English labor market. Annals of Economics and Statistics/Annales d'Économie et de Statistique, 169-185.

Ruffle, B. J., and Sosis, R. (2006). Cooperation and the in-group-out-group bias: A field test on Israeli kibbutz members and city residents. Journal of Economic Behavior and Organization, 60, 147-163.

Schüller, D., Tauchmann, H., Upmann, T., and Weimar, D. (2014). Pro-social behavior in the TV show "Come Dine With Me": An empirical investigation. Journal of Economic Psychology, 45, 44-55.

Slonim, R., and Guillen, P. (2010). Gender selection discrimination: Evidence from a trust game. Journal of Economic Behavior and Organization, 76, 385-405.

Solnick, S. J. (2001). Gender differences in the ultimatum game. Economic Inquiry 39: 189-200.

Strabac, Z., and Listhaug, O. (2008). Anti-Muslim prejudice in Europe: A multilevel analysis of survey data from 30 countries. Social Science Research, 37, 268-286.

Wall, G. (2011). Outwit, outplay, outcast? Sex discrimination in voting behaviour in the reality television show Survivor. New Zealand Economic Papers, 45, 183-193.

Wallace, S., Nazroo, J., and Bécares, L. (2016). Cumulative effect of racial discrimination on the mental health of ethnic minorities in the United Kingdom. American journal of public health, 106, 1294-1300.

Williamson, M. (2010). Female celebrities and the media: The gendered denigration of the 'ordinary' celebrity. Celebrity studies, 1, 118-120.

Wood, M., Hales, J., Purdon, S., Sejersen, T., and Hayllar, O. (2009). A test for racial discrimination in recruitment practice in British cities. Department for Work and Pensions Research Report, 607. Department for Work and Pensions, London.

Zschirnt, E., and Ruedin, D. (2016). Ethnic discrimination in hiring decisions: a meta-analysis of correspondence tests 1990-2015. Journal of Ethnic and Migration Studies, 42, 1115-1134. 